\title{
Atrial fibrillation hospitalization is associated with exposure to fine particulate air pollutants
}

\author{
Hsiu Hao Lee ${ }^{1}$, Shih Chun Pan², Bing Yu Chen ${ }^{3}$, Shih Hsiang Lo ${ }^{1}$ and Yue Leon Guo 2,3,4*
}

\begin{abstract}
Background: Although air pollutants have been associated with cardiopulmonary mortality, their effects on the occurrence of atrial fibrillation (Afib) remain unclear. This study examined the association between ambient air pollutants and Afib occurrence.

Methods: Using a representative sample from the National Health Insurance Database of Taiwan, we applied a case-crossover study design to explore the associations between air pollutants and patients hospitalized with Afib from 2006 to 2011. The event day was when a patient was hospitalized with Afib, and the control days were the same days of the following weeks of the same month. The association between Afib occurrence and levels of ambient air pollutants (including particulate matter [PM] $2.5 \mathrm{PM}_{10}, \mathrm{NO}_{2}, \mathrm{SO}_{2}$, and $\mathrm{O}_{3}$ ) was examined after adjusting for temperature and relative humidity. A two-pollutant model was used to examine the effect of the second pollutant when the first pollutant was determined to be significantly related to Afib.
\end{abstract}

Results: During 2006-2011, 670 patients hospitalized with the first onset of Afib were identified. The occurrence of Afib was associated with $\mathrm{PM}_{2.5}$, in which a $22 \%(95 \%$ confidence interval = 3-44\%) increase was related to an interquartile range increase $(26.2 \mu \mathrm{g} / \mathrm{m} 3)$ on the same day and a $19 \%$ (95\% confidence interval $=0-40 \%)$ increase on the second day. A two-pollutant model was applied, and the results indicated that the effect of $\mathrm{PM}_{2.5}$ was significantly associated with the occurrence of Afib. Patients aged over 65 years with DM and with hyperlipidemia were more susceptible to the effect of $\mathrm{PM}_{2.5}$.

Conclusions: In conclusion, the occurrence of Afib was associated with short-term exposure to fine particulate air pollutants in the general population.

Keywords: Air pollution, Atrial fibrillation, Particulate matter, Case-crossover

\section{Introduction}

Atrial fibrillation (Afib) is the most commonly sustained cardiac arrhythmia, and it occurs in approximately $2 \%$ of the general population [1, 2]. Afib is associated with reduced quality of life, increased thromboembolic events, and increased death rates [3-5]. In particular, Afibinduced stroke is often severe and results in long-term disability or death [1]. Although advancements in the

\footnotetext{
*Correspondence: leonguo@ntu.edu.tw

${ }^{2}$ Institution of Occupational Medicine and Industrial Hygiene, National Taiwan University College of Public Health, Room 703, No. 17, Xu-Zhou Road, Taipei 100, Taiwan

${ }^{3}$ National Institute of Environmental Health Sciences, National Health Research Institutes, 10 F, Bldg F, 3 Yuanqu Street, Taipei 11503, Taiwan Full list of author information is available at the end of the article
}

diagnosis and treatment of Afib have improved its prognosis, understanding the causes of Afib can help understand the methods of preventing this severe medical condition. In recent years, fine particulate matter $<2.5 \mathrm{~mm}$ in aerodynamic diameter $\left(\mathrm{PM}_{2.5}\right)$ has been increasingly associated with the onset or attack of cardiac events including sudden cardiac death, heart failure, and myocardial infarctions [6-8]. $\mathrm{PM}_{2.5}$ is produced through direct emissions from local and regional sources such as motor vehicles in addition to upwind secondary particles from burning fossil fuels [9]. A meta-analysis showed that a $10-\mu \mathrm{g} / \mathrm{m}^{3}$ increment in $\mathrm{PM}_{2.5}$ was associated with a $1.04 \%$ (95\% confidence interval $[\mathrm{CI}]=0.52-1.56 \%$ ) increase in the risk of all-cause mortality and $0.84 \%$ (95\% CI $=0.41-1.28 \%)$ 
increase in the risk of cardiovascular mortality [10]. In addition, stroke was associated with $\mathrm{PM}_{2.5}$, with increased risks of $1.1 \%(95 \% \mathrm{CI}=1.1-1.2 \%)$ per $10 \mu \mathrm{g} / \mathrm{m}^{3}$ increase in $\mathrm{PM}_{2.5}$ [11]. However, whether air pollution induces Afib in the general population is uncertain. In the current study, we determined whether exposure to ambient air pollutants is associated with an increased risk of Afib hospitalization. We used a representative national health database to examine this hypothesis.

\section{Methods}

Our data source was the National Health Insurance (NHI) program in Taiwan. The NHI program, which was implemented on March 1, 1995, is a compulsory health insurance program. Under this nationwide program, up to $99 \%$ of the nation's population receive myriad health care services, including outpatient services, inpatient care, traditional Chinese medicine, dental care, prenatal care or obstetric services, physical therapy, preventive health care, home care, and rehabilitation. The NHI maintains a comprehensive, validated patient database containing information on patient diagnoses and drug prescriptions. The quality of its information on prescription use, diagnoses, and hospitalizations is excellent [12] The NHI sample files, which are constructed and managed by the National Health Research Institutes, consist of comprehensive use and enrollment information for a randomly selected sample of 1 million NHI beneficiaries, representing approximately $5 \%$ of enrollees in Taiwan in 2000. A multistage stratified systematic sampling design was used to create the sample, and no statistically significant differences in sex or age were observed between the sample group and all enrollees. All information allowing a specific patient to be identified is encrypted. The confidentiality of the data is maintained in accordance with the data protection regulations of the Bureau of National Health Insurance (BNHI).

Patients diagnosed with Afib (based on the International Classification of Diseases, Ninth Revision, clinical modification code 437.31) for the first time from the inpatient claims database between January 1, 2006 and December 31, 2011 were retrieved as potential study participants. Patients with any previous inpatient and outpatient diagnosis of Afib before this admission were excluded. The Institutional Review Board of the Taiwan National Health Research Institutes approved this study (IRB No.: NHRI-107-EMSP02). Ultimately, 670 patients with Afib hospitalization for the first time were analyzed.

Complete air-quality-related data from the Taiwanese Environmental Protection Administration were retrieved from 77 fixed-site air quality monitoring stations from 2006 to 2011. Each station routinely monitored hourly criteria air pollutants, including $\mathrm{CO}$ (parts per million, ppm), NO (parts per billion, ppb), NO2 (ppb), NOx (ppb), SO2 (ppb.), O3 (ppb), O3 8 h maximum (ppb; defined as the maximum average level of ozone for 8 consecutive $\mathrm{h} / \mathrm{d})$, PM2.5 ( $\mu \mathrm{g} / \mathrm{m} 3)$, and PM10 PM2.5 $(\mu \mathrm{g} / \mathrm{m} 3)$, as well as ambient temperature $\left({ }^{\circ} \mathrm{C}\right)$. The monitoring stations were fully automated, and they routinely monitored the levels of pollutants including $\mathrm{SO} 2$ (through ultraviolet fluorescence), PM (through beta-ray absorption), NO2 (through ultraviolet fluorescence), $\mathrm{CO}$ (through nondispersive infrared photometry), and O3 (through ultraviolet photometry). PM2.5 concentrations in Taiwan have been measured continuously since 2006. The availability of the monitoring network for PM2.5 provided an opportunity to investigate the effect of PM2.5 on the onset of Afib. For each day, hourly air pollution data were obtained from the monitoring stations. The 24-h average level of each pollutant was computed according to the hourly mean levels of the day. For each day, for any individual pollutant with 8 or more missing hourly average values, the daily average level was treated as a missing value.

Data were analyzed using the case-crossover technique, which is an alternative to using Poisson time-series regression models for studying the short-term effects of air pollutants [13]. A time-stratified approach was used for case-crossover analysis. Time was stratified into separate months so that referent days could be selected as the days falling on the same day of the week within the same month to serve as the index day. Air pollution levels during the case period were compared with exposures occurring on all referent days. This stratified referent selection scheme minimizes bias because of stagnant air pollution time-series data [14]. The associations between Afib and air pollutants were estimated through conditional logistic regression. All statistical analyses were performed using the SAS package (version 9.3, SAS Institute Inc., Cary, NC, USA). Both single- and two-pollutant models were fitted with various combinations of pollutants (up to two pollutants per model) to assess the stability of the effect of air pollutants. Levels of exposure to air pollutants were entered into the models as continuous variables. The daily average temperature, as a meteorological variable that might play a confounding role, was included in the model. Odds ratios (ORs) and their 95\% confidence intervals (Cis) were calculated for the interquartile range (IQR) differences (between the 25th and the 75th percentile). The temporal association between air pollutants and hospital admission for Afib development was further stratified according to time lags. Summary estimates for lag zero (Day 1) refer to the risk of an event per increment in air pollution on the day of the event. Lag 1 (Day 2) refers to risk estimates per increment in air pollutant concentrations 1 day before the event. Single lags from 0 to 4 (Day 1, 2, 3, 4 and 5) and cumulative lag 0-4 (Day1-5) were analyzed. Potential risk 
Table 1 The characteristics and comorbidities of study population $(n=670)$

\begin{tabular}{llll}
\hline Variables & $\mathrm{N}$ & $(\%)$ & Mean \pm SD \\
\hline Age & 670 & $(100.0)$ & $70.5 \pm 14.0$ \\
$<65$ & 188 & $(28.1)$ & \\
$\geq 65$ & 482 & $(71.9)$ & \\
Gender & & & \\
Male & 343 & $(51.2)$ & \\
Comorbidity & & & \\
Coronary artery disease & 447 & $(66.7)$ \\
Congestive heart failure & 287 & $(42.8)$ \\
Hypertension & 529 & $(79.0)$ \\
Hyperlipidemia & 257 & $(38.4)$ \\
COPD & 112 & $(16.7)$ \\
Diabetes mellitus & 213 & $(31.8)$ \\
Chronic kidney disease & 57 & $(8.5)$ & \\
\hline
\end{tabular}

factors for the development of Afib [2, 15, 16], including age, diabetes mellitus, hypertension, dyslipidemia, COPD, congestive heart failure, coronary artery disease, and chronic kidney disease, were incorporated.

\section{Result}

The characteristics and comorbidities of patients included in this study are presented in Table 1 . During the 6 years of the study, 670 patients ( $51.2 \%$ men) were diagnosed with Afib for the first time and were hospitalized. Temperature, relative humidity, and monitored criteria air pollutants during 2006-2011 are provided in Table 2. Spearman correlation coefficients among these variables are presented in Table 3. There was a certain degree of correlation among PM2.5 and other pollutants, especially PM2.5 and PM10 $(r=0.95), \mathrm{PM} 2.5$ and $\mathrm{CO}(r=$
$0.66), \mathrm{PM} 2.5$ and $\mathrm{NO} 2(r=0.61), \mathrm{PM} 2.5$ and NOx $(r=$ $0.52)$, PM2.5 and O3 $8 \mathrm{~h}$ maximum $(r=0.62)$, and PM2.5 and SO2 $(r=0.63)$.

The adjusted OR for the occurrence of Afib in a single-pollutant model is shown in Table 4. The occurrence of Afib was associated with PM2.5, in which a $22 \%(95 \%$ $\mathrm{CI}=3-44 \%)$ increase was related to an IQR increase in PM2.5 $(26.2 \mu \mathrm{g} / \mathrm{m} 3)$ on the same day (lag 0) and a $19 \%$ (95\% CI $=0-40 \%)$ increase on the second day. None of the other pollutants was associated with Afib occurrence. A two-pollutant model was applied, and the results indicated that the effect of PM2.5 remained significantly associated with Afib occurrence, with the addition of any of the climate factors or air pollutants (Table 5). PM10 was not used in the two-pollutant analysis because of its high correlation $(r=0.95)$ with PM2.5.

The multivariate stratified analysis for Afib development is shown in Fig. 1. Patients aged greater than 65 years, without coronary artery disease, without chronic kidney disease, without COPD, with DM, and with hyperlipidemia, might be susceptible to the effect of PM2.5. Patients without congestive heart failure were more susceptible to the effect of PM2.5 than those with congestive heart failure.

\section{Discussion}

This is the first study to demonstrate that $\mathrm{PM}_{2.5}$ might trigger Afib in the general population with no previously diagnosed Afib. The average levels of $\mathrm{PM}_{2.5}$ and IQR during the study period were 34 and $26.2 \mu \mathrm{g} / \mathrm{m}^{3}$, respectively. The identified association between $\mathrm{PM}_{2.5}$ and Afib occurrence cannot be explained by climatic factors or the other air pollutants.

This is not the first study to examine the potential association between exposure to PM and Afib development. Bunch determined that Afib hospitalization did not

Table 2 Distribution of temperature, relative humidity, and air pollutants during 2006-2011

\begin{tabular}{|c|c|c|c|c|c|c|c|c|}
\hline \multirow[t]{2}{*}{ Pollutant } & \multirow[t]{2}{*}{ Min } & \multirow[t]{2}{*}{ Mean } & \multirow[t]{2}{*}{ SD } & \multirow[t]{2}{*}{ Max } & \multicolumn{3}{|c|}{ Percentiles } & \multirow[t]{2}{*}{ IQR } \\
\hline & & & & & 25th & 50th & 75th & \\
\hline $\mathrm{PM}_{2.5}, \mu \mathrm{g} / \mathrm{m}^{3}$ & 1.53 & 34.04 & 18.79 & 164.21 & 19.13 & 30.14 & 45.37 & 26.23 \\
\hline $\mathrm{PM}_{10}, \mu \mathrm{g} / \mathrm{m}^{3}$ & 5.19 & 60.08 & 33.63 & 1214.07 & 35.71 & 52.28 & 78.21 & 42.49 \\
\hline $\mathrm{cO}, \mathrm{ppm}$ & 0.04 & 0.44 & 0.16 & 2.42 & 0.33 & 0.43 & 0.54 & 0.21 \\
\hline NO, ppb & 0.65 & 4.10 & 2.87 & 77.01 & 2.49 & 3.28 & 4.69 & 2.20 \\
\hline $\mathrm{NO}_{2}, \mathrm{ppb}$ & 0.61 & 15.24 & 6.32 & 56.48 & 10.51 & 14.57 & 19.05 & 8.54 \\
\hline $\mathrm{NO}_{x}, \mathrm{ppb}$ & 2.30 & 19.4 & 8.19 & 129.92 & 13.69 & 17.79 & 23.25 & 9.56 \\
\hline $\mathrm{SO}_{2}, \mathrm{ppb}$ & 0.26 & 3.87 & 1.71 & 25.14 & 2.72 & 3.51 & 4.58 & 1.86 \\
\hline $\mathrm{O}_{3}, \mathrm{ppb}$ & 0.73 & 29.17 & 10.53 & 86.29 & 21.35 & 27.81 & 35.70 & 14.35 \\
\hline $\mathrm{O}_{3}, \max 8 \mathrm{~h}, \mathrm{ppb}$ & 1.41 & 47.81 & 18.35 & 140.25 & 33.78 & 45.30 & 59.97 & 26.19 \\
\hline AMB_TEMP, ${ }^{\circ} \mathrm{C}$ & 2.31 & 24.01 & 4.81 & 52.15 & 20.42 & 25.05 & 28.11 & 7.69 \\
\hline $\mathrm{RH}, \%$ & 1.49 & 74.91 & 7.09 & 98.40 & 70.66 & 74.97 & 79.32 & 8.66 \\
\hline
\end{tabular}


Table 3 Spearman correlation coefficients of temperature, relative humidity, and air pollutants

\begin{tabular}{|c|c|c|c|c|c|c|c|c|c|c|c|}
\hline & $\mathrm{PM}_{2.5}$ & $\mathrm{PM}_{10}$ & $\mathrm{CO}$ & NO & $\mathrm{NO}_{2}$ & NOx & $\mathrm{O}_{3}$ & $\mathrm{O}_{3}{ }^{\mathrm{a}}$ & $\mathrm{SO}_{2}$ & $\mathrm{RH}$ & TEMP \\
\hline $\mathrm{PM}_{2.5}$ & 1 & 0.95 & 0.66 & 0.07 & 0.61 & 0.52 & 0.47 & 0.62 & 0.63 & -0.33 & -0.31 \\
\hline $\mathrm{PM}_{10}$ & & 1 & 0.61 & 0.07 & 0.59 & 0.50 & 0.47 & 0.61 & 0.64 & -0.38 & -0.32 \\
\hline $\mathrm{CO}$ & & & 1 & 0.47 & 0.82 & 0.84 & 0.16 & 0.28 & 0.47 & -0.07 & -0.60 \\
\hline NO & & & & 1 & 0.52 & 0.70 & -0.52 & -0.27 & 0.28 & 0.08 & -0.24 \\
\hline $\mathrm{NO}_{2}$ & & & & & 1 & 0.95 & 0.06 & 0.23 & 0.54 & -0.12 & -0.56 \\
\hline NOx & & & & & & 1 & -0.06 & 0.13 & 0.51 & -0.08 & -0.56 \\
\hline $\mathrm{O}_{3}$ & & & & & & & 1 & 0.88 & 0.23 & -0.32 & -0.04 \\
\hline $\mathrm{O}_{3}, \max 8 \mathrm{~h}$ & & & & & & & & 1 & 0.41 & -0.39 & 0.05 \\
\hline $\mathrm{SO}_{2}$ & & & & & & & & & 1 & -0.33 & -0.04 \\
\hline $\mathrm{RH}$ & & & & & & & & & & 1 & -0.03 \\
\hline TEMP & & & & & & & & & & & 1 \\
\hline
\end{tabular}

a $8 \mathrm{~h}$ maximum

RH Relative humidity, TEMP Ambient temperature

increase with short-term elevations in exposure to PM2.5 (mean $10-11 \mu \mathrm{g} / \mathrm{m} 3$ ). Most studies have investigated patients wearing implantable cardioverter defibrillators (ICDs) and discovered associations between particulate air pollutants and attacks of Afib or ventricular fibrillation [17-22]. A study on ICD patients revealed that the possibility of Afib increased by $26 \%$ (95\% CI $8-47 \%$ ) for each $6.0-\mu \mathrm{g} / \mathrm{m} 3$ increase in PM2.5 [23]. However, those wearing ICDs were distinct from the general population. First, heart failure is one of the most common causes of ICD implantation for the primary or secondary prevention of ventricular arrhythmias. A high risk of Afib has been reported among patients with heart failure [24, 25]. Most of the aforementioned studies have included patients with coronary artery disease. Ischemic heart disease events increase with PM exposure [26]; thus, they may affect Afib incidence, potentially biasing an analysis of atrial arrhythmias. Therefore, the findings indicated that the effects of PM on the occurrence of Afib in patients wearing ICDs observed in highly susceptible groups cannot be easily extrapolated to the general population.

Table 4 Adjusted $O R^{*}$ for atrial fibrillation onset in a single-pollutant model ${ }^{a}$ in the case-crossover study in Taiwan during 2006-2011

\begin{tabular}{|c|c|c|c|c|c|c|c|c|c|c|}
\hline \multirow[t]{3}{*}{ Day } & \multicolumn{2}{|c|}{ Pollutants } & \multicolumn{2}{|c|}{$\mathrm{PM}_{2.5-10}$} & \multicolumn{2}{|c|}{$\mathrm{PM}_{10}$} & \multicolumn{2}{|l|}{$\mathrm{CO}$} & \multicolumn{2}{|l|}{ NO } \\
\hline & \multicolumn{2}{|l|}{$\mathrm{PM}_{2.5}$} & & & & & & & & \\
\hline & OR & $95 \% \mathrm{Cl}$ & OR & $95 \% \mathrm{Cl}$ & OR & $95 \% \mathrm{Cl}$ & OR & $95 \% \mathrm{Cl}$ & OR & $95 \% \mathrm{Cl}$ \\
\hline 1 & 1.22 & $(1.03-1.44)$ & 1.00 & $(0.91-1.09)$ & 1.08 & $(0.95-1.24)$ & 0.94 & $(0.84-1.06)$ & 0.98 & $(0.93-1.04)$ \\
\hline 2 & 1.19 & $(1.00-1.40)$ & 1.00 & $(0.92-1.10)$ & 1.08 & $(0.94-1.25)$ & 1.02 & $(0.91-1.14)$ & 1.03 & $(0.98-1.09)$ \\
\hline 3 & 1.02 & $(0.86-1.21)$ & 0.92 & $(0.80-1.06)$ & 0.95 & $(0.80-1.14)$ & 1.00 & $(0.90-1.12)$ & 1.02 & $(0.97-1.08)$ \\
\hline 4 & 0.96 & $(0.81-1.14)$ & 1.03 & $(0.95-1.11)$ & 1.02 & $(0.88-1.17)$ & 0.99 & $(0.88-1.11)$ & 1.02 & $(0.97-1.07)$ \\
\hline 5 & 1.00 & $(0.85-1.18)$ & 1.00 & $(0.90-1.10)$ & 1.00 & $(0.86-1.16)$ & 0.97 & $(0.86-1.09)$ & 0.98 & $(0.93-1.04)$ \\
\hline \multirow[t]{3}{*}{$1-5$} & 1.29 & $(0.99-1.68)$ & 0.99 & $(0.83-1.18)$ & 1.15 & $(0.89-1.48)$ & 1.20 & $(0.98-1.46)$ & 1.04 & $(0.96-1.14)$ \\
\hline & \multicolumn{2}{|l|}{$\mathrm{NO}_{2}$} & \multicolumn{2}{|l|}{ NOx } & \multicolumn{2}{|l|}{$\mathrm{SO}_{2}$} & \multicolumn{2}{|l|}{$\mathrm{O}_{3}$} & \multicolumn{2}{|c|}{$\mathrm{O}_{3} \_8 \mathrm{~h} \_\max$} \\
\hline & OR & $95 \% \mathrm{Cl}$ & OR & $95 \% \mathrm{Cl}$ & OR & $95 \% \mathrm{Cl}$ & OR & $95 \% \mathrm{Cl}$ & OR & $95 \% \mathrm{Cl}$ \\
\hline 1 & 0.95 & $(0.81-1.11)$ & 0.94 & $(0.84-1.06)$ & 1.01 & $(0.90-1.14)$ & 1.02 & $(0.87-1.19)$ & 0.98 & $(0.83-1.16)$ \\
\hline 2 & 0.99 & $(0.84-1.16)$ & 1.02 & $(0.91-1.14)$ & 1.01 & $(0.90-1.14)$ & 1.09 & $(0.94-1.27)$ & 1.10 & $(0.93-1.29)$ \\
\hline 3 & 0.92 & $(0.79-1.08)$ & 1.00 & $(0.90-1.12)$ & 0.92 & $(0.81-1.04)$ & 1.07 & $(0.92-1.24)$ & 1.02 & $(0.87-1.20)$ \\
\hline 4 & 0.97 & $(0.83-1.14)$ & 0.99 & $(0.88-1.11)$ & 1.00 & $(0.89-1.13)$ & 1.02 & $(0.88-1.18)$ & 1.02 & $(0.87-1.20)$ \\
\hline 5 & 0.95 & $(0.81-1.12)$ & 0.97 & $(0.86-1.09)$ & 0.98 & $(0.87-1.11)$ & 1.02 & $(0.88-1.18)$ & 0.94 & $(0.80-1.10)$ \\
\hline $1-5$ & 0.93 & $(0.72-1.20)$ & 1.00 & $(0.83-1.21)$ & 1.02 & $(0.83-1.26)$ & 1.16 & $(0.92-1.46)$ & 1.08 & $(0.83-1.41)$ \\
\hline
\end{tabular}

OR calculated for interquartile range increases of PM2.5 $\left(26.2 \mu \mathrm{g} / \mathrm{m}^{3}\right), \mathrm{PM} 10\left(42.5 \mu \mathrm{gg} / \mathrm{m}^{3}\right), \mathrm{CO}(0.2 \mathrm{ppm}), \mathrm{NO}(2.2 \mathrm{ppb}), \mathrm{NO}_{2}(8.5 \mathrm{ppb}), \mathrm{NOx}(9.6 \mathrm{ppb}), \mathrm{SO} 2(1.9 \mathrm{ppb})$, $\mathrm{O}_{3}(14.4 \mathrm{ppb}), \mathrm{O}_{3}, \max 8 \mathrm{~h}(26.2 \mathrm{ppb})$, and ambient temperature (AMB_TEMP) $\left(7.7^{\circ} \mathrm{C}\right)$

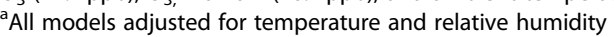


Table 5 Adjusted $\mathrm{OR}^{\mathrm{a}}$ for atrial fibrillation onset in twopollutant model ${ }^{\mathrm{b}}$ using case-crossover study in Taiwan during 2006-2011

\begin{tabular}{|c|c|c|c|}
\hline Pollutant & Day & $\mathrm{OR}^{\mathrm{a}}$ & $(95 \% \mathrm{Cl})$ \\
\hline \multirow[t]{6}{*}{$\mathrm{PM}_{2.5}$ adj. $\mathrm{CO}$} & 1 & 1.43 & $(1.14-1.79)$ \\
\hline & 2 & 1.18 & $(0.94-1.47)$ \\
\hline & 3 & 0.94 & $(0.75-1.18)$ \\
\hline & 4 & 0.87 & $(0.70-1.09)$ \\
\hline & 5 & 1.00 & $(0.83-1.20)$ \\
\hline & $1-5$ & 1.39 & $(1.03-1.86)$ \\
\hline \multirow[t]{6}{*}{$\mathrm{PM}_{2.5}$ adj. $\mathrm{NO}$} & 1 & 1.19 & $(1.01-1.41)$ \\
\hline & 2 & 1.13 & $(0.95-1.34)$ \\
\hline & 3 & 1.00 & $(0.84-1.19)$ \\
\hline & 4 & 0.95 & $(0.81-1.13)$ \\
\hline & 5 & 1.00 & $(0.85-1.18)$ \\
\hline & $1-5$ & 1.27 & $(0.97-1.66)$ \\
\hline \multirow[t]{6}{*}{$\mathrm{PM}_{2.5}$ adj. $\mathrm{NO}_{2}$} & 1 & 1.33 & $(1.10-1.61)$ \\
\hline & 2 & 1.25 & $(1.03-1.52)$ \\
\hline & 3 & 1.09 & $(0.89-1.33)$ \\
\hline & 4 & 0.98 & $(0.81-1.18)$ \\
\hline & 5 & 1.03 & $(0.85-1.25)$ \\
\hline & $1-5$ & 1.57 & $(1.14-2.18)$ \\
\hline \multirow[t]{6}{*}{$\mathrm{PM}_{2.5}$ adj. $\mathrm{SO}_{2}$} & 1 & 1.25 & $(1.03-1.52)$ \\
\hline & 2 & 1.21 & $(0.99-1.47)$ \\
\hline & 3 & 1.11 & $(0.91-1.36)$ \\
\hline & 4 & 0.96 & $(0.79-1.16)$ \\
\hline & 5 & 1.01 & $(0.83-1.23)$ \\
\hline & $1-5$ & 1.42 & $(1.03-1.96)$ \\
\hline \multirow[t]{6}{*}{$\mathrm{PM}_{2.5}$ adj. $\mathrm{O}_{3}$} & 1 & 1.22 & $(1.02-1.45)$ \\
\hline & 2 & 1.14 & $(0.95-1.36)$ \\
\hline & 3 & 0.98 & $(0.81-1.78)$ \\
\hline & 4 & 0.96 & $(0.80-1.15)$ \\
\hline & 5 & 0.98 & $(0.82-1.18)$ \\
\hline & $1-5$ & 1.25 & $(0.93-1.68)$ \\
\hline \multirow[t]{6}{*}{$\mathrm{PM}_{2.5}$ adj. $\mathrm{O}_{3}, \max 8 \mathrm{hr}$} & 1 & 1.30 & $(1.07-1.57)$ \\
\hline & 2 & 1.15 & $(0.95-1.40)$ \\
\hline & 3 & 1.00 & $(0.82-1.22)$ \\
\hline & 4 & 0.95 & $(0.79-1.56)$ \\
\hline & 5 & 1.04 & $(0.86-1.27)$ \\
\hline & $1-5$ & 1.37 & $(0.99-1.91)$ \\
\hline
\end{tabular}

${ }^{a} \mathrm{OR}$ calculated for an interquartile range increases of $\mathrm{PM}_{2.5}\left(26.2 \mu \mathrm{g} / \mathrm{m}^{3}\right), \mathrm{CO}$ (0.2 ppm), $\mathrm{SO}_{2}(1.9 \mathrm{ppb}), \mathrm{NO}(2.2 \mathrm{ppb}), \mathrm{NO}_{2}(8.5 \mathrm{ppb}), \mathrm{NOx}(9.6 \mathrm{ppb}), \mathrm{O}_{3}(14.3$ $\mathrm{ppb}), \mathrm{O}_{3}{ }^{*}(26.2 \mathrm{ppb})$ and $\mathrm{PM}_{10}\left(42.5 \mu \mathrm{g} / \mathrm{m}^{3}\right)$

${ }^{\mathrm{b}}$ All models adjusted for temperature and relative humidity

Potential intriguing mechanisms may increase Afib risk with particulate air pollution exposure. Acute alterations in autonomic tone and impaired heart rate variability have been documented in humans [27-29] and animals [30, 31] exposed to PM2.5. Moreover, particulate air pollution is linked to $\mathrm{C}$-reactive protein, a marker of inflammation [32-34]. Changes in autonomic tone $[35,36]$, inflammation and oxidative stress [37, 38], atrial ischemia [39], and atrial pressure [39, 40] may induce Afib. Other admissions because of cardiac ischemia were increased by PM2.5 [41, 42]. An increase in PM in patients with moderate or severe heart failure increases right ventricular pressure, which in turn increases right atrial pressure [43]. Therefore, particulate air pollution causes Afib.

As already stated, the causes of Afib onset, whether initial or recurrent, were complex and numerous. Individuals with chronic comorbid health conditions may have an increased risk of cardiovascular morbidity and mortality associated with air pollutants levels [44]. The subgroup analysis study revealed that patients aged over 65 years without coronary artery disease, chronic kidney disease, and COPD but with DM and hyperlipidemia might be susceptible to the adverse effects of PM2.5. Patients without congestive heart failure were more susceptible to the adverse effect of PM2.5 than those with congestive heart failure. As mentioned in related reports $[44,45]$, the frailty of older adults, among whom the prevalence of chronic cardiopulmonary diseases is higher, is the most likely reason why patients aged over 60 years have a higher risk of Afib admission due to the effects of PM2.5. A relationship between DM and Afib [46] exists, and this paper suggests that patients with DM, reduced heart rate variability, increased C-reactive protein levels, and elevated inflammatory markers [47] be aware of the effects of PM2.5 to prevent Afib admission. Inconsistent results may derive from factors related to the disease itself. Patients diagnosed with hyperlipidemia are more likely to use statins; statin use may reduce the risk of Afib [44]. Causes of Afib onset other than PM2.5 might have a less substantial effect on patients with hyperlipidemia. Therefore, the effects of PM2.5 on Afib onset became significant for those with hyperlipidemia. Patients with cardiovascular disease, CKD, and COPD are more likely to reduce their exposure to air pollution and take heart rhythm control medications, thus reducing their risk of developing arrhythmia. Patients diagnosed with congestive heart failure are more likely to use beta-blockers, which may reduce the risk of Afib [48]. Although the results of the subgroup analysis in our study were inconclusive, our paper argues for randomized control trials to ascertain which subgroup is more susceptible to the effect of PM2.5 on AF development.

This study has several strengths. First, Afib cases and the study population were retrieved from the BNHI database, which covers most of the Taiwanese population. By June 2014, 23 million people in Taiwan were 


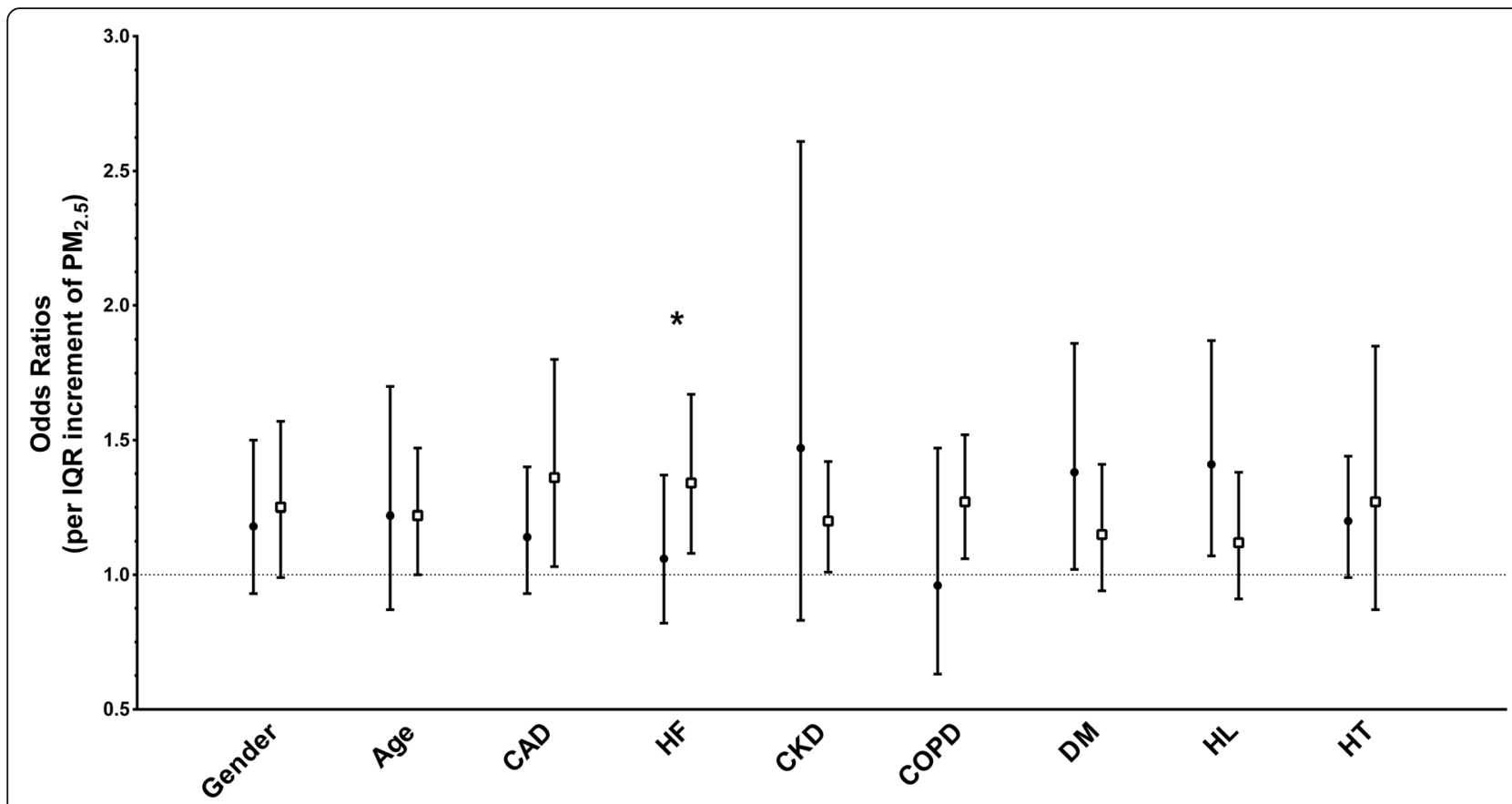

Fig. 1 Adjusted OR for atrial fibrillation onset in subgroup analysis using case-crossover study in Taiwan during 2006-2011. CAD: coronary artery disease; HF: heart failure; CKD: chronic obstructive pulmonary disease; DM: diabetes mellitus; HL: hyperlipidemia; HT: hypertension. ': female; age $<65$; with comorbidity. a: male; age $\geq 65$; without comorbidity. *: interaction $P$ value less than 0.05

enrolled in the NHI program, yielding a coverage rate of $>99.5 \%$. The quality of information from the NHI database on prescription use, diagnoses, and hospitalizations is excellent [49]. To ensure the accuracy of the claims files, the BNHI conducts quarterly expert reviews on a random sample of every 50-100 ambulatory and inpatient claims. False reports of diagnostic information result in a hefty penalty from the BNHI [12]. Second, we did not include patients with a previous diagnosis of Afib; therefore, the observation of increased Afib in the present study was likely the first onset of Afib. Third, only those diagnosed with Afib in emergency departments who were then hospitalized were counted among our cases. Therefore, the diagnosis was highly valid.

This study has some potential limitations. First, several possible variables associated with Afib development were not considered, including blood pressure, smoking, family history, and alcohol consumption. Communicating with patients directly was impractical for us because the data were anonymized. However, because each participant served as a lone control in this case-crossover study, numerous variables were unlikely to bias our overall findings. Such factors could predispose the onset of Afib, but this is unlikely; nevertheless, because control days were selected from the same day of various weeks of the month, probable random errors, not systematic errors, could be introduced. Thus, the observed association might have been inclined toward the null hypothesis. Second, because the NHI in Taiwan was established on March 1, 1995, participants in this study with an Afib diagnosis before that date could not be identified. However, patients who were diagnosed with Afib before 1995 and did not seek medical attention between March 1, 1995 and December 31, 2005 may be rare.

\section{Conclusions}

In conclusion, compared with that at $19 \mu \mathrm{g} / \mathrm{m} 3$, ambient PM2.5 at $45 \mu \mathrm{g} / \mathrm{m} 3$ was associated with an approximately $22 \%$ increase in Afib in the general population. This equates to an $8.6 \%$ increase in Afib per $10 \mu \mathrm{g} / \mathrm{m} 3$ increase in PM2.5. Preventive strategies are warranted to reduce the risk of Afib when PM2.5 is elevated.

\footnotetext{
Abbreviations

Afib: Atrial fibrillation; CAD: Coronary artery disease; Cis: Confidence intervals: CKD: Chronic kidney diseae; CO: Carbon monoxide; COPD: Chronic obstructive pulmonary disease; DM: Diabetes mellitus; HF: Heart failure; HL: Hyperlipidemia; HT: Hypertension; ICD-10: International Classification of Diseases, 10th Revision; IQR: Interquartile range; Max: Maximum; Min: Minimum; NO2: Nitrogen dioxides; ORs: Odds ratios; PM: Particle matter; PM2.5, PM10: Particulate matter $\leq 2.5-\mu \mathrm{m}$ (or $<10-\mu \mathrm{m})$ in diameter; RH: Relative humidity; SD: Standard deviation; SO2: Sulfur dioxide; TEMP: Temperature
}

\section{Acknowledgments}

This study is based in part on data obtained from the National Health Insurance Research Database provided by the Bureau of National Health Insurance, Department of Health and managed by the National Health Research Institutes. We thank the funding from National Institute of 
Environmental Health Sciences, National Health Research Institutes, Taiwan. (NHRI-107-EMGP02 \& NHRI-108-EMGP02) The interpretation and conclusions contained herein do not represent those of the Bureau of National Health Insurance, Department of Health, or National Health Research Institutes.

\section{Authors' contributions}

YLG conceived of the study and supervised all aspects of its implementation. $\mathrm{HHL}$ and SCP completed the analyses and drafted the content. BYC and SHL assisted with the study design and revised the content. All authors helped to conceptualize ideas, interpret findings and review drafts of the manuscript. All authors approved the final manuscript.

\section{Funding}

National Institute of Environmental Health Sciences, National Health Research Institutes, Taiwan (NHRI-107-EMGP02 \& NHRI-108-EMGP02).

\section{Availability of data and materials}

Weather and air pollutants data are available from Environmental Protection Administration, ROC (Taiwan): https://www.epa.gov.tw/mp.asp?mp=epaen; hospital admission data, has not deposited in publicly available repositories, are obtained from the Bureau of National Health Insurance, ROC (Taiwan). Hospital admission data is available from the corresponding author on reasonable request.

\section{Ethics approval and consent to participate}

All information allowing a specific patient to be identified has been encrypted. The confidentiality of the data abides by the data regulations of the Bureau of National Health Insurance. The Institutional Review Board (IRB) of Taiwan National Health Research Institutes approved this study (IRB No.: NHRI-107-EMSP02).

\section{Consent for publication}

Not applicable.

\section{Competing interests}

The authors declare that they have no competing interests.

\section{Author details}

'Department of Internal Medicine, Taipei City Hospital, Zhongxing Branch, No. 145, Zhengzhou Rd., Datong Dist, Taipei City 10341, Taiwan. ${ }^{2}$ Institution of Occupational Medicine and Industrial Hygiene, National Taiwan University College of Public Health, Room 703, No. 17, Xu-Zhou Road, Taipei 100, Taiwan. ${ }^{3}$ National Institute of Environmental Health Sciences, National Health Research Institutes, 10 F, Bldg F, 3 Yuanqu Street, Taipei 11503, Taiwan. ${ }^{4}$ Environmental and Occupational Medicine, National Taiwan University and NTU Hospital, Taipei 100, Taiwan.

\section{Received: 26 January 2019 Accepted: 18 December 2019}

\section{Published online: 30 December 2019}

\section{References}

1. European Heart Rhythm A, European Association for Cardio-Thoracic S, Camm AJ, Kirchhof P, Lip GY, Schotten U, Savelieva I, Ernst S, Van Gelder IC, Al-Attar N, et al. Guidelines for the management of atrial fibrillation: the Task Force for the Management of Atrial Fibrillation of the European Society of Cardiology (ESC). Eur Heart J. 2010;31(19):2369-429.

2. Lin LY, Lee CH, Yu CC, Tsai CT, Lai LP, Hwang JJ, Chen PC, Lin JL. Risk factors and incidence of ischemic stroke in Taiwanese with nonvalvular atrial fibrillation-- a nation wide database analysis. Atherosclerosis. 2011;217(1): 292-5.

3. Kirchhof P, Auricchio A, Bax J, Crijns H, Camm J, Diener HC, Goette A, Hindricks G, Hohnloser S, Kappenberger L, et al. Outcome parameters for trials in atrial fibrillation: executive summary. Eur Heart J. 2007;28(22):2803-17.

4. Go AS, Hylek EM, Phillips KA, Chang Y, Henault LE, Selby JV, Singer DE. Prevalence of diagnosed atrial fibrillation in adults: national implications for rhythm management and stroke prevention: the AnTicoagulation and risk factors in atrial fibrillation (ATRIA) study. JAMA. 2001;285(18):2370-5.

5. Thrall G, Lane D, Carroll D, Lip GY. Quality of life in patients with atrial fibrillation: a systematic review. Am J Med. 2006;119(5):448.e441-19.

6. Brook RD, Rajagopalan S, Pope CA 3rd, Brook JR, Bhatnagar A, Diez-Roux AV Holguin F, Hong Y, Luepker RV, Mittleman MA, et al. Particulate matter air pollution and cardiovascular disease: an update to the scientific statement from the American Heart Association. Circulation. 2010;121(21):2331-78.

7. Peters A, Dockery DW, Muller JE, Mittleman MA. Increased particulate air pollution and the triggering of myocardial infarction. Circulation. 2001; 103(23):2810-5

8. Levy D, Sheppard L, Checkoway H, Kaufman J, Lumley T, Koenig J, Siscovick D. A case-crossover analysis of particulate matter air pollution and out-ofhospital primary cardiac arrest. Epidemiology. 2001;12(2):193-9.

9. Link MS, Dockery DW. Air pollution and the triggering of cardiac arrhythmias. Curr Opin Cardiol. 2010;25(1):16-22.

10. Atkinson RW, Kang S, Anderson HR, Mills IC, Walton HA. Epidemiological time series studies of PM2.5 and daily mortality and hospital admissions: a systematic review and meta-analysis. Thorax. 2014;69(7):660-5.

11. Shah AS, Lee KK, MCAllister DA, Hunter A, Nair H, Whiteley W, Langrish JP, Newby DE, Mills NL. Short term exposure to air pollution and stroke: systematic review and meta-analysis. BMJ. 2015;350:h1295.

12. Tseng $\mathrm{CH}$. Mortality and causes of death in a national sample of diabetic patients in Taiwan. Diabetes Care. 2004;27(7):1605-9.

13. Levy D, Lumley T, Sheppard L, Kaufman J, Checkoway H. Referent selection in case-crossover analyses of acute health effects of air pollution. Epidemiology. 2001;12(2):186-92.

14. Mittleman MA. Optimal referent selection strategies in case-crossover studies: a settled issue. Epidemiology. 2005;16(6):715-6.

15. Digby GC, Baranchuk A. Sleep apnea and atrial fibrillation; 2012 update. Curr Cardiol Rev. 2012;8(4):265-72.

16. Whang W, Davidson KW, Conen D, Tedrow UB, Everett BM, Albert CM. Global psychological distress and risk of atrial fibrillation among women: the Women's health study. J Am Heart Assoc. 2012;1(3):e001107.

17. Rich DQ, Mittleman MA, Link MS, Schwartz J, Luttmann-Gibson H, Catalano PJ, Speizer FE, Gold DR, Dockery DW. Increased risk of paroxysmal atrial fibrillation episodes associated with acute increases in ambient air pollution. Environ Health Perspect. 2006;114(1):120-3.

18. Rich DQ, Schwartz J, Mittleman MA, Link M, Luttmann-Gibson H, Catalano PJ, Speizer FE, Dockery DW. Association of short-term ambient air pollution concentrations and ventricular arrhythmias. Am J Epidemiol. 2005;161(12): 1123-32.

19. Dockery DW, Luttmann-Gibson H, Rich DQ, Link MS, Mittleman MA, Gold DR, Koutrakis P, Schwartz JD, Verrier RL. Association of air pollution with increased incidence of ventricular tachyarrhythmias recorded by implanted cardioverter defibrillators. Environ Health Perspect. 2005;113(6):670-4.

20. Rich DQ, Kim MH, Turner JR, Mittleman MA, Schwartz J, Catalano PJ, Dockery DW. Association of ventricular arrhythmias detected by implantable cardioverter defibrillator and ambient air pollutants in the St Louis, Missouri metropolitan area. Occup Environ Med. 2006;63(9):591-6.

21. Berger A, Zareba W, Schneider A, Ruckerl R, Ibald-Mulli A, Cyrys J, Wichmann $\mathrm{HE}$, Peters A. Runs of ventricular and supraventricular tachycardia triggered by air pollution in patients with coronary heart disease. J Occup Environ Med. 2006;48(11):1149-58.

22. Pope CA 3rd, Burnett RT, Thurston GD, Thun MJ, Calle EE, Krewski D, Godleski JJ. Cardiovascular mortality and long-term exposure to particulate air pollution: epidemiological evidence of general pathophysiological pathways of disease. Circulation. 2004;109(1):71-7.

23. Link MS, Luttmann-Gibson H, Schwartz J, Mittleman MA, Wessler B, Gold DR, Dockery DW, Laden F. Acute exposure to air pollution triggers atrial fibrillation. J Am Coll Cardiol. 2013:62(9):816-25.

24. Ben Morrison T, Jared Bunch T, Gersh BJ. Pathophysiology of concomitant atrial fibrillation and heart failure: implications for management. Nat Clin Pract Cardiovasc Med. 2009;6(1):46-56.

25. Wang TJ, Massaro JM, Levy D, Vasan RS, Wolf PA, D'Agostino RB, Larson MG, Kannel WB, Benjamin EJ. A risk score for predicting stroke or death in individuals with new-onset atrial fibrillation in the community: the Framingham heart study. JAMA. 2003;290(8):1049-56.

26. Pope CA 3rd, Muhlestein JB, May HT, Renlund DG, Anderson JL, Horne BD Ischemic heart disease events triggered by short-term exposure to fine particulate air pollution. Circulation. 2006;114(23):2443-8.

27. Zanobetti A, Gold DR, Stone PH, Suh HH, Schwartz J, Coull BA, Speizer FE. Reduction in heart rate variability with traffic and air pollution in patients with coronary artery disease. Environ Health Perspect. 2010;118(3):324-30.

28. Gold DR, Litonjua A, Schwartz J, Lovett E, Larson A, Nearing B, Allen G, Verrier $\mathrm{M}$, Cherry $\mathrm{R}$, Verrier R. Ambient pollution and heart rate variability. Circulation. 2000;101(11):1267-73. 
29. Schwartz J, Litonjua A, Suh H, Verrier M, Zanobetti A, Syring M, Nearing B, Verrier $\mathrm{R}$, Stone $\mathrm{P}$, MacCallum $\mathrm{G}$, et al. Traffic related pollution and heart rate variability in a panel of elderly subjects. Thorax. 2005;60(6):455-61.

30. Chen LC, Hwang JS. Effects of subchronic exposures to concentrated ambient particles (CAPs) in mice. IV. Characterization of acute and chronic effects of ambient air fine particulate matter exposures on heart-rate variability. Inhal Toxicol. 2005;17(4-5):209-16.

31. Corey LM, Baker C, Luchtel DL. Heart-rate variability in the apolipoprotein E knockout transgenic mouse following exposure to Seattle particulate matter. J Toxicol Environ Health A. 2006;69(10):953-65.

32. Peters $A$, Frohlich $M$, Doring $A$, Immervoll $T$, Wichmann $H E$, Hutchinson $W L$, Pepys MB, Koenig W. Particulate air pollution is associated with an acute phase response in men; results from the MONICA-Augsburg study. Eur Heart J. 2001;22(14):1198-204.

33. Pekkanen J, Brunner EJ, Anderson HR, Tiittanen P, Atkinson RW. Daily concentrations of air pollution and plasma fibrinogen in London. Occup Environ Med. 2000;57(12):818-22.

34. Schwartz J. Air pollution and blood markers of cardiovascular risk. Environ Health Perspect. 2001;109(Suppl 3):405-9.

35. Bettoni M, Zimmermann M. Autonomic tone variations before the onset of paroxysmal atrial fibrillation. Circulation. 2002;105(23):2753-9.

36. Lombardi F, Tarricone D, Tundo F, Colombo F, Belletti S, Fiorentini C. Autonomic nervous system and paroxysmal atrial fibrillation: a study based on the analysis of RR interval changes before, during and after paroxysmal atrial fibrillation. Eur Heart J. 2004;25(14):1242-8.

37. Aviles RJ, Martin DO, Apperson-Hansen C, Houghtaling PL, Rautaharju P, Kronmal RA, Tracy RP, Van Wagoner DR, Psaty BM, Lauer MS, et al. Inflammation as a risk factor for atrial fibrillation. Circulation. 2003;108(24): 3006-10.

38. Chung MK, Martin DO, Sprecher D, Wazni O, Kanderian A, Carnes CA, Bauer JA, Tchou PJ, Niebauer MJ, Natale A, et al. C-reactive protein elevation in patients with atrial arrhythmias: inflammatory mechanisms and persistence of atrial fibrillation. Circulation. 2001;104(24):2886-91.

39. White CW, Kerber RE, Weiss HR, Marcus ML. The effects of atrial fibrillation on atrial pressure-volume and flow relationships. Circ Res. 1982;51(2):205-15.

40. Kamkin A, Kiseleva I, Wagner KD, Lozinsky I, Gunther J, Scholz H. Mechanically induced potentials in atrial fibroblasts from rat hearts are sensitive to hypoxia/reoxygenation. Pflugers Arch. 2003:446(2):169-74.

41. Pekkanen J, Peters A, Hoek G, Tiittanen P, Brunekreef B, de Hartog J, Heinrich J, Ibald-Mulli A, Kreyling WG, Lanki T, et al. Particulate air pollution and risk of ST-segment depression during repeated submaximal exercise tests among subjects with coronary heart disease: the exposure and risk assessment for fine and ultrafine particles in ambient air (ULTRA) study. Circulation. 2002;106(8):933-8.

42. Delfino RJ, Gillen DL, Tjoa T, Staimer N, Polidori A, Arhami M, Sioutas C, Longhurst J. Electrocardiographic ST-segment depression and exposure to traffic-related aerosols in elderly subjects with coronary artery disease. Environ Health Perspect. 2011;119(2):196-202.

43. Rich DQ, Freudenberger RS, Ohman-Strickland P, Cho Y, Kipen HM. Right heart pressure increases after acute increases in ambient particulate concentration. Environ Health Perspect. 2008;116(9):1167-71.

44. Zheng Q, Liu H, Zhang J, Chen D. The effect of ambient particle matters on hospital admissions for cardiac arrhythmia: a multi-city case-crossover study in China. Environ Health. 2018;17(1):60.

45. Milojevic A, Wilkinson P, Armstrong B, Bhaskaran K, Smeeth L, Hajat S. Shortterm effects of air pollution on a range of cardiovascular events in England and Wales: case-crossover analysis of the MINAP database, hospital admissions and mortality. Heart. 2014;100(14):1093-8.

46. Tadic M, Cuspidi C. Type 2 diabetes mellitus and atrial fibrillation: from mechanisms to clinical practice. Arch Cardiovasc Dis. 2015;108(4):269-76.

47. Aune D, Feng T, Schlesinger S, Janszky I, Norat T, Riboli E. Diabetes mellitus, blood glucose and the risk of atrial fibrillation: a systematic review and meta-analysis of cohort studies. J Diabetes Complicat. 2018;32(5):501-11.

48. Dezsi CA, Szentes V. The real role of beta-blockers in daily cardiovascular therapy. Am J Cardiovasc Drugs. 2017;17(5):361-73.

49. Hsieh CY, Chen CH, Li CY, Lai ML. Validating the diagnosis of acute ischemic stroke in a National Health Insurance claims database. J Formos Med Assoc Taiwan yi zhi. 2015;114(3):254-9.

\section{Publisher's Note}

Springer Nature remains neutral with regard to jurisdictional claims in published maps and institutional affiliations.

\section{Ready to submit your research? Choose BMC and benefit from:}

- fast, convenient online submission

- thorough peer review by experienced researchers in your field

- rapid publication on acceptance

- support for research data, including large and complex data types

- gold Open Access which fosters wider collaboration and increased citations

- maximum visibility for your research: over $100 \mathrm{M}$ website views per year

At BMC, research is always in progress.

Learn more biomedcentral.com/submissions 